\title{
Short-Run Control Chart for Multiproducts with Multi-Items Based on Unequal Means and Variances
}

\author{
Soroush Avakh Darestani and Neda Aminpour \\ Faculty of Industrial and Mechanical Engineering, Islamic Azad University, Qazvin Branch, Qazvin, Iran \\ Correspondence should be addressed to Soroush Avakh Darestani; soroushavakh@yahoo.com
}

Received 31 October 2013; Revised 8 May 2014; Accepted 26 May 2014; Published 25 September 2014

Academic Editor: Shey-Huei Sheu

Copyright (C) 2014 S. Avakh Darestani and N. Aminpour. This is an open access article distributed under the Creative Commons Attribution License, which permits unrestricted use, distribution, and reproduction in any medium, provided the original work is properly cited.

\begin{abstract}
Statistical process control (SPC) is one of the most important statistical tools for monitoring production processes. It can be effectively designed and implemented when the process or product specifications are consecutively observed from a mass production condition. Normally, short-cycle productions do not have sufficient data to implement SPC. This research introduced how to design and implement short-run control chart for batch production conditions. Monitoring critical specifications of supplied parts to automotive industry was proposed. The results revealed that unequal variables followed normal distribution and can be fluctuated over time for the purpose of monitoring multiple products for each product including multidimensions with unequal means and variances from the central line to control the chart. Out-of-control signals and nonrandom patterns can be recognized on the developed short-run control chart accordingly.
\end{abstract}

\section{Introduction}

Statistical process control (SPC) is one of the most important statistical tools for monitoring production processes. Shortrun control charts are used in any situation where very little (i.e., less than 20 subgroups) or no data exists about the process, and, therefore, chart parameters cannot be estimated.

In this paper, we present how to use short-run control chart in monitoring the multiproducts with their multi-items. According to the proposed method for establishing short-run control chart, the production process of a first-tier producer of automotive industry was selected for this study.

Historically, traditional SPC methods were developed for application to high volume manufacturing processes, that is, mass production environments. Since Shewhart's era, many techniques, technologies, and philosophies have been introduced, creating a wide array of manufacturing environments other than just a mass production one [1].

Statistics is the science of decision making using facts, specifically measured data. Although quality is a subjective concept, statistical techniques have played an important role in the history of quality [2]. SPC has its origins in the 1920s with a set of problem-solving tools which may be applied to any process. The control chart is the most powerful of the SPC tools [3].

The importance of quality has been long recognized as vital to both competition and survival in the business world. A study has been done in Malaysian industry based on implementation of SPC in eight companies and the research result shows that almost all companies in this study have found that SPC is very useful to improve their quality process [4].

The most important phase in SPC is selection of indicators which should be monitored. Short-run control charts are designed to be useful with small lot production runs with limited amounts of data. In order to monitor dissimilar characteristics on the same chart, the plot points must be coded. This coding of data is what allows different units of measure and different product characteristics to be plotted on the same chart [5].

One of the primary tools used in the statistical control of a process is the control chart. Created by Walter Shewhart in 1924, the Shewhart control chart gives a crisp picture of the state of a process by plotting the data produced by a process on a chart bound by upper and lower specification limits [6]. 
Many manufacturing organizations feel they cannot utilize statistical process control (SPC) charts because their average product run length is too short. Infrequent, short production runs do not lend themselves to the usual variable $\bar{X}$ and range $(R)$ control charts [7].

Statistical control of a process by variables is accomplished through the use of a pair of control charts $\bar{X}$ and $R$. The control limits for $\bar{X}$ and $R$ charts are based on data taken from at least 20 to 25 samples of product from the process [8].

In many processes, the run is completed before the central line and control limits can be calculated. This fact is especially true for a job shop with small lot sizes. Furthermore, as companies practice JIT production, short runs are becoming more common [9].

The following gives a brief description of existing SPC control chart.

$Z$-MR chart is a chart of standardized individual observations $(Z)$ and moving ranges (MR) from a short-run process. Short-run charts provide a solution for simultaneously monitoring characteristics by pooling and standardizing the data in various ways. Standardizing allows you to evaluate data from different runs by interpreting a single control chart [10].

Also, short-run $p$ charts were introduced by Nedumaran and Leon [11]. They proposed that the standard $p$ charts could be modified to obtain a chart which would appropriately represent processes where little or no data was available [11].

Under certain conditions, dividing to a $\delta$, or difference from nominal can provide a means for providing statistical control of a short-run process. The purpose of this method is to describe the $\delta$ control chart and the conditions appropriate for its use. Other types of difference control charts are compared with the $\delta$ chart and the appropriate application for each is discussed. A brief case analysis describes the use of the $\delta$ chart in a metal fabrication operation. Short-run processes represent a challenge for traditional SPC control charting techniques [12].

Short-run processes often do not have enough data in each run to produce good estimates of process parameters. This will cause the reduction of the performance and efficiency of control chart. A common solution to this problem is considering a single machine or process to produce many different parts, or different products. To solve this problem, a method based on nonconformity degree and fuzzy membership functions has been developed for controlling these processes. This method is simple and useable. By these membership functions, all observations of different processes convert into the same scaled data and they can be monitored in the same control chart with satisfactory performance [13].

Elam and Case develop the theory that is needed to apply the two-stage short-run theory of control charting to $(\bar{X}, s)$ charts. It then uses this theory to derive the equations for calculating the factors required to determine two-stage short-run control limits for $(\bar{X}, s)$ charts. Also, equations to calculate conventional control chart constants for $(\bar{X}, s)$ charts are derived. Additionally, this paper gives advantages of two-stage short-run $(\bar{X}, s)$ control charts [14].

In this paper, we developed a revised short-run control chart; the production process of a first-tier producer of automotive industry was selected for this study. The product of the operation process included lamp bracket of Pride, lock protection of Samand, lock protection of 206, and Lower holder of injector. SPC implementation was concentrated on daily tests which could monitor compounding operation output.

\section{Methodology}

Literature review reveals the high value of short-run control chart for monitoring batch production processes in which the data are not enough to construct control chart. In this context, the problem is to properly design a short-run control chart for different industries. From Shewhart control chart, it is assumed that $99.73 \%$ of points are plotted within the control limits. Short-run $R$ chart can be used for monitoring application of unequal characteristics in supply chain of automotive industry. Each point on the control chart is supposed to be plotted within the control limits according to [15]

$$
\begin{gathered}
\mathrm{UCL}_{R}=D_{4} \bar{R}, \\
\mathrm{LCL}_{R}=D_{3} \bar{R}, \\
\text { then } \mathrm{LCL}_{\mathrm{R}}<R<\mathrm{UCL}_{R}, \\
\text { Divided by } \bar{R} \frac{D_{3} \bar{R}}{\bar{R}}<R<\frac{D_{4} \bar{R}}{\bar{R}} .
\end{gathered}
$$

The modified control chart is obtained as follows:

$$
\begin{gathered}
\text { Standardized } \mathrm{UCL}_{R}=D_{4} \\
\text { Standardized } \mathrm{CL}_{R}=1 \\
\text { Standardized } \mathrm{LCL}_{R}=D_{3} .
\end{gathered}
$$

The aim is to develop the revised control chart for different characteristics and different products with unequal means and variances. Assume the following:

$n=$ the number of subgroups belonging to specific characteristics, $i=1,2, \ldots, n$,

$m=$ the number of quality characteristics, $j=$ $1,2, \ldots, m$,

$P=$ the number of products, $k=1,2, \ldots, p$,

$R_{i j k}$ : mean range of the $i$ th sample for the $j$ th parameter for $k$ th product,

Target $\bar{R}_{j k}$ : target $R$ for $j$ th parameter or characteristics for $k$ th product (obtainable from historical data),

Short-run $R$ point

$=$ Standardized Unequal Range (SUR)

$$
=\frac{R_{i j k}}{\text { Target } \bar{R}_{j k}} \text {. }
$$


Likewise, the same method can be proposed for shortrun $X$ control chart. It is assumed that $99.73 \%$ of points are plotted within the control limits. Therefore, each point should fall into the $\bar{X}$ control chart as follows:

$$
\begin{aligned}
& \mathrm{UCL}_{\bar{X}}=\overline{\bar{X}}+A_{2} \bar{R}, \\
& \mathrm{LCL}_{\bar{X}}=\overline{\bar{X}}-A_{2} \bar{R} ;
\end{aligned}
$$

Then $\operatorname{LCL}_{\bar{X}}<\bar{X}<\mathrm{UCL}_{\bar{X}} \quad[15]$.

Substituting the formulas we obtain the following results:

$$
\overline{\bar{X}}-A_{2} \bar{R}<\bar{X}<\overline{\bar{X}}+A_{2} \bar{R} .
$$

Then, $\overline{\bar{X}}$ can be subtracted from the two sides of the inequality:

$$
-A_{2} \bar{R}<\bar{X}-\overline{\bar{X}}<A_{2} \bar{R} .
$$

Eventually, the two sides of the inequality can be divided by $\bar{R}$ as follows:

$$
-A_{2}<\frac{\bar{X}-\overline{\bar{X}}}{\bar{R}}<A_{2} .
$$

Short-run point on $\bar{X}$ can be calculated as follows:

Short-run $\bar{X}$ point

$$
\text { = Standardized Unequal Mean (SUM) }
$$

$$
=\frac{\bar{X}_{i j k}-\text { Target } \overline{\bar{X}}_{j k}}{\bar{R}_{j} k} \text {. }
$$

$\bar{X}_{i j k}$ is mean of $i$ th sample for $j$ th parameter or characteristics for $k$ th product.

Target $\overline{\bar{X}}_{j k}$ is mean of $\bar{X}$ for $j$ th parameter or characteristics for $k$ th product (obtainable from historical data).

According to the proposed method for establishing shortrun control chart, the production process of a first-tier producer of automotive industry was selected for this study. The product of operation process included lamp bracket of Pride, lock protection of Samand, lock protection of Peugeot 206, and lower holder of injector. SPC implementation was concentrated on daily tests which could monitor compounding operation output. For each indicator of each product, 6 samples were considered which were measured 4 times. To develop the control charts for this research, we used the Minitab software. Based on the control chart rules, the results should be within upper and lower control limits. Usually, illustrating $\bar{X}, R$ control chart for each product, and indicator individually is difficult. Because the number of the points on a control chart is not enough, illustrating short-run control chart for doing the tests could lead to monitoring all 4 products and indicators simultaneously.
TABLE 1: Basic statistics of four SPC products.

\begin{tabular}{lccc}
\hline Product & Parameter & Observations & Mean \\
\hline \multirow{4}{*}{$\begin{array}{l}\text { Lamp bracket } \\
\text { of Pride }\end{array}$} & Length to the edge of bent & 24 & 40.00 \\
& Width to the edge of bent & 24 & 200.01 \\
& Punch diameter & 24 & 140.01 \\
\hline \multirow{2}{*}{ Lock } & Height of bent 1 & 24 & 10.80 \\
protection of & Height of bent 2 & 24 & 40.00 \\
Samand & Length & 24 & 300.00 \\
& Distance to punch center & 24 & 100.01 \\
\hline \multirow{3}{*}{$\begin{array}{l}\text { Lock } \\
\text { protection of }\end{array}$} & Height of bent & 24 & 20.00 \\
206 & Length & 24 & 300.01 \\
& Width & 24 & 200.01 \\
\hline \multirow{2}{*}{$\begin{array}{l}\text { Lower holder } \\
\text { of injector }\end{array}$} & Punch diameter & 24 & 10.20 \\
& Height of bent 1 & 24 & 300.01 \\
\hline
\end{tabular}

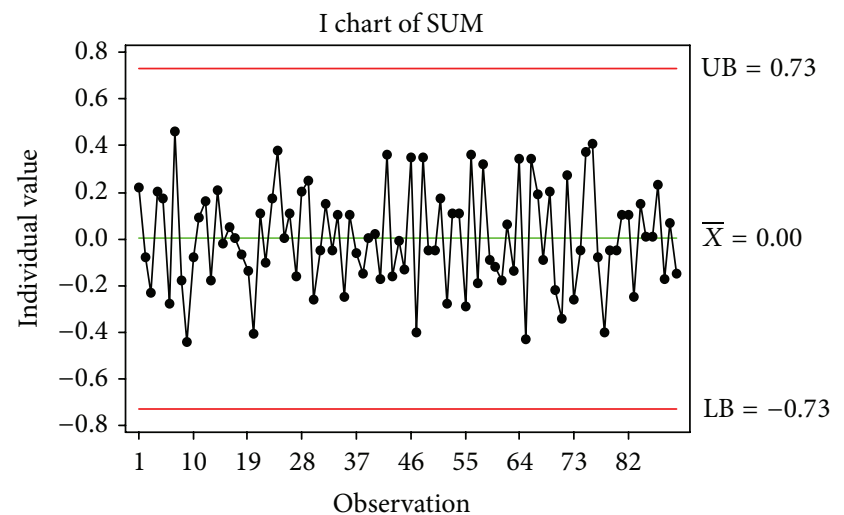

FIgURE 1: Short-run $\bar{X}$.

\section{Results}

Based on the methodology, a total of 90 observations with sample size of 4 were considered for this research. The gathered data are represented in Table 1.

According to the developed equations (3) and (8), the data related to the tests were standardized and short-run $\bar{X}, R$ was developed in this respect (Figures 1 and 2). Figure 1 is provided based on four products: lamp bracket of Pride, lock protection of Samand, lock protection of 206, and lower holder of injector. The first 24 points fluctuated by first product's parameters such as height of bent, length to the edge of bent, width to the edge of bent, and punch diameter; the second 24 points by lock protection of Samand's parameters such as height of bent 1 , height of bent 2 , length, and distance to punch center; the third 24 points by lock protection of 206's parameters such as height of bent, length, width, and punch diameter; and the fourth 18 points by lower holder of injector's parameters such as length, height of bent 1 , and height of bent 2. The control limits were standardized according to (7). 


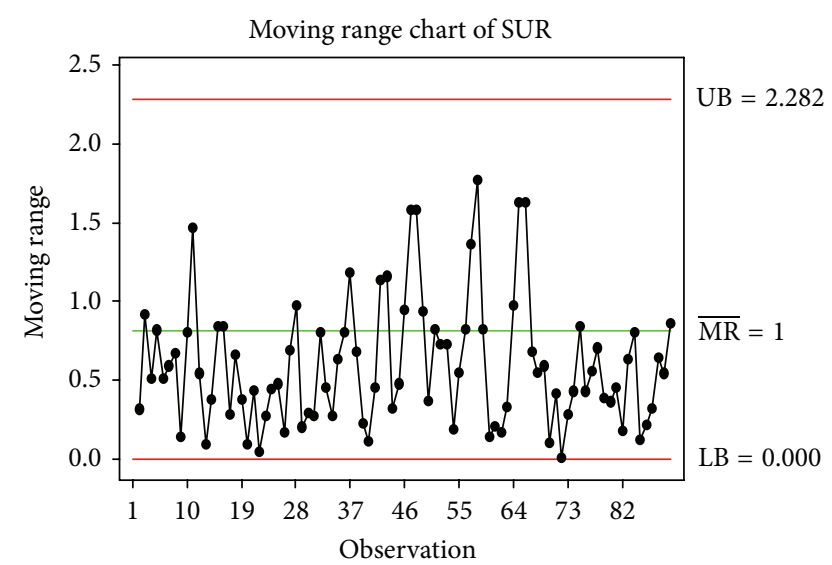

FIGURE 2: Short-run $R$.

Also, Figure 2 provides short-run $R$ chart for products and their indicators. The control limits are standardized according to (2).

\section{Conclusions}

It can be concluded that unequal variables can be monitored simultaneously for batch production industries, which helps save monitoring time for products and processes. In practice, when the same characteristics of different parts are to be monitored statistically, short-run charts are efficient as insufficient data do not support normality assumption of the control charts. In this context, short-run control charts can be useful. To improve SPC characteristic over time, outof-control signals were tested on short-run control charts. It was shown that the data had no out-of-control point and no nonnormal signals and could be used as a standard for implementing SPC. Further research can be conducted to investigate capability process indices of control chart in unequal characteristic conditions and short-run control chart for multiple products and multiple items with unequal fuzzybased mean and variance.

\section{Conflict of Interests}

The authors declare that there is no conflict of interests regarding the publication of this paper.

\section{References}

[1] L. C. Alwan, Statistical Process Analysis, McGraw-Hill, 1st edition, 2000.

[2] M. Xie and T. N. Goh, "Statistical techniques for quality," The TQM Magazine, vol. 11, no. 4, pp. 238-241, 1999.

[3] D. C. Montgomery, G. C. Runger, and N. F. Hubele, Engineering Statistics, John Wiley \& Sons, New York, NY, USA, 4th edition, 2007.

[4] M. N. Ab Rahman, R. Mohd Zain, Z. Mohd Nopiah et al., "The implementation of SPC in Malaysian manufacturing companies," European Journal of Scientific Research, vol. 26, no. 3, pp. 453-464, 2009.
[5] S. A. Wise and D. C. Fair, Innovative Control Charting: American Society for Quality, 1997.

[6] D. C. Montgomery, Introduction to Statistical Quality Control, John Wiley \& Sons, New York, NY, USA, 2001.

[7] G. E. Hayes, Quality Assurance: Management and Technology, Charger Productions, Capistrano Beach, Calif, USA, 1974.

[8] V. E. Sower, J. G. Motwani, and M. J. Savoie, "S Charts for short run statistical process control," International Journal of Quality \& Reliability Management, vol. 11, no. 6, pp. 50-56, 1994.

[9] D. H. Besterfield, Quality Control, Prentice Hall, New York, NY, USA, 8th edition, 2009.

[10] Minitab, Minitab (Version 15.1.0.0), Minitab Inc., 2006.

[11] G. Nedumaran and V. J. Leon, "P-chart control limits based on a small number of subgroups," Quality Engineering, vol. 11, no. 1, pp. 1-9, 1998.

[12] V. E. Sower, J. G. Motwani, and M. J. Savoie, " $\beta$ charts for short run statistical process control," International Journal of Quality \& Reliability Management, vol. 11, no. 6, pp. 50-56, 1994.

[13] M. Aminnayeri, E. A. Torkamani, M. Davodi, and F. Ramtin, "Short-run process control based on non-conformity degree," in Proceedings of the World Congress on Engineering (WCE '10), vol. 3, pp. 2273-2276, London, UK, July 2010.

[14] M. E. Elam and K. E. Case, "Two-stage short-run ( $\bar{X}, s)$ control charts," Quality Engineering, vol. 17, no. 1, pp. 95-107, 2005.

[15] F. M. Gryna, Quality Planning and Analysis, McGraw-Hill, New York, NY, USA, 4th edition, 2001. 

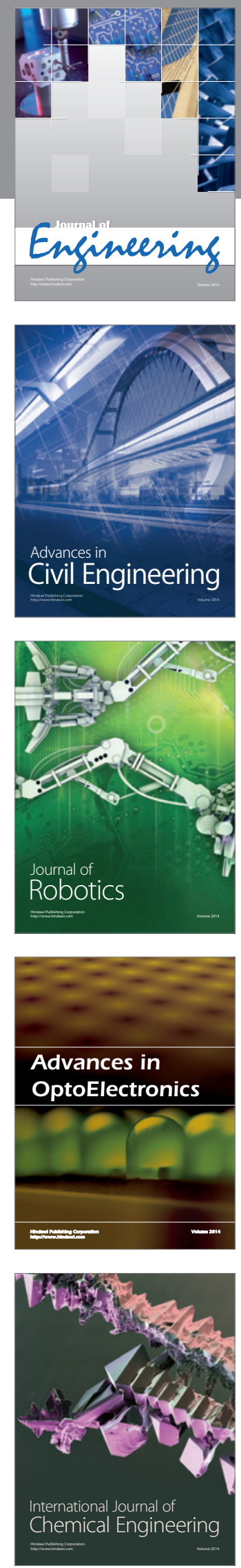

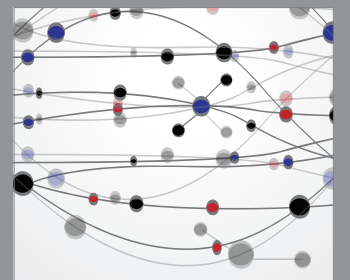

The Scientific World Journal
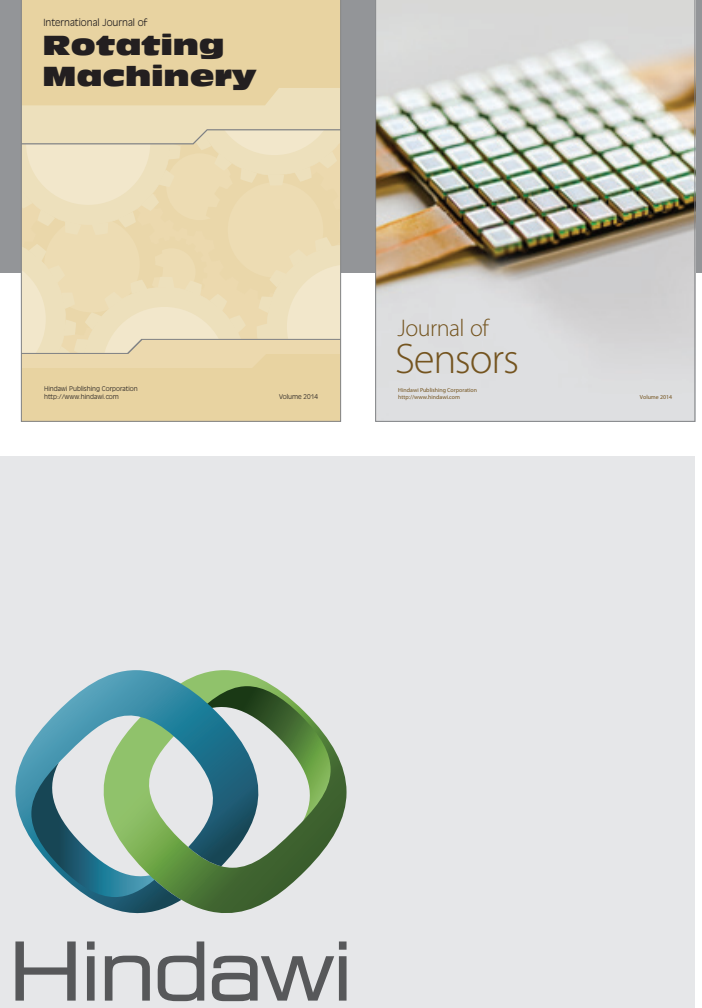

Submit your manuscripts at http://www.hindawi.com
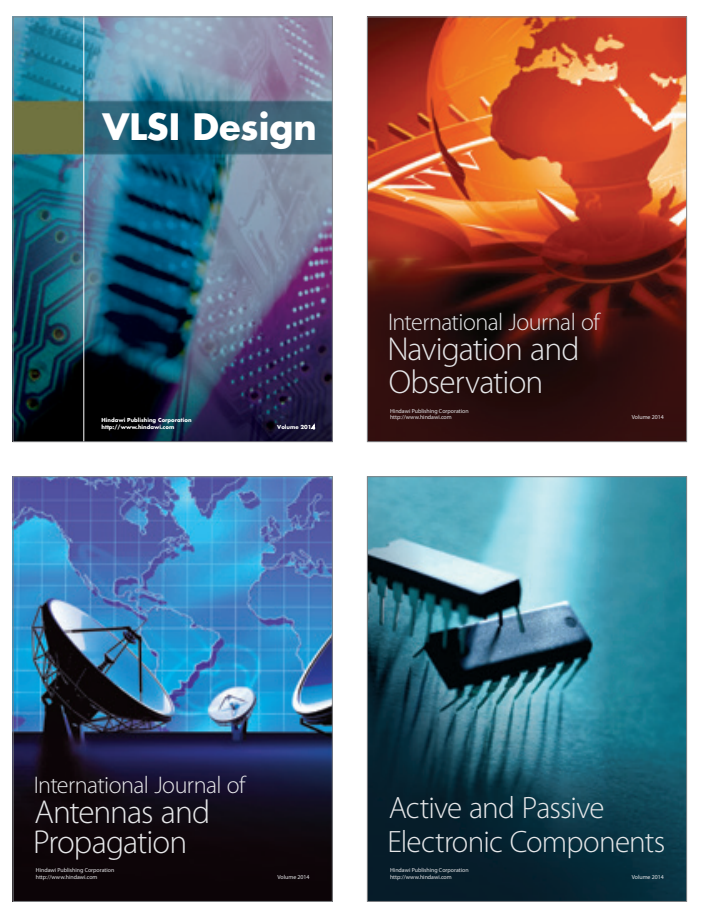
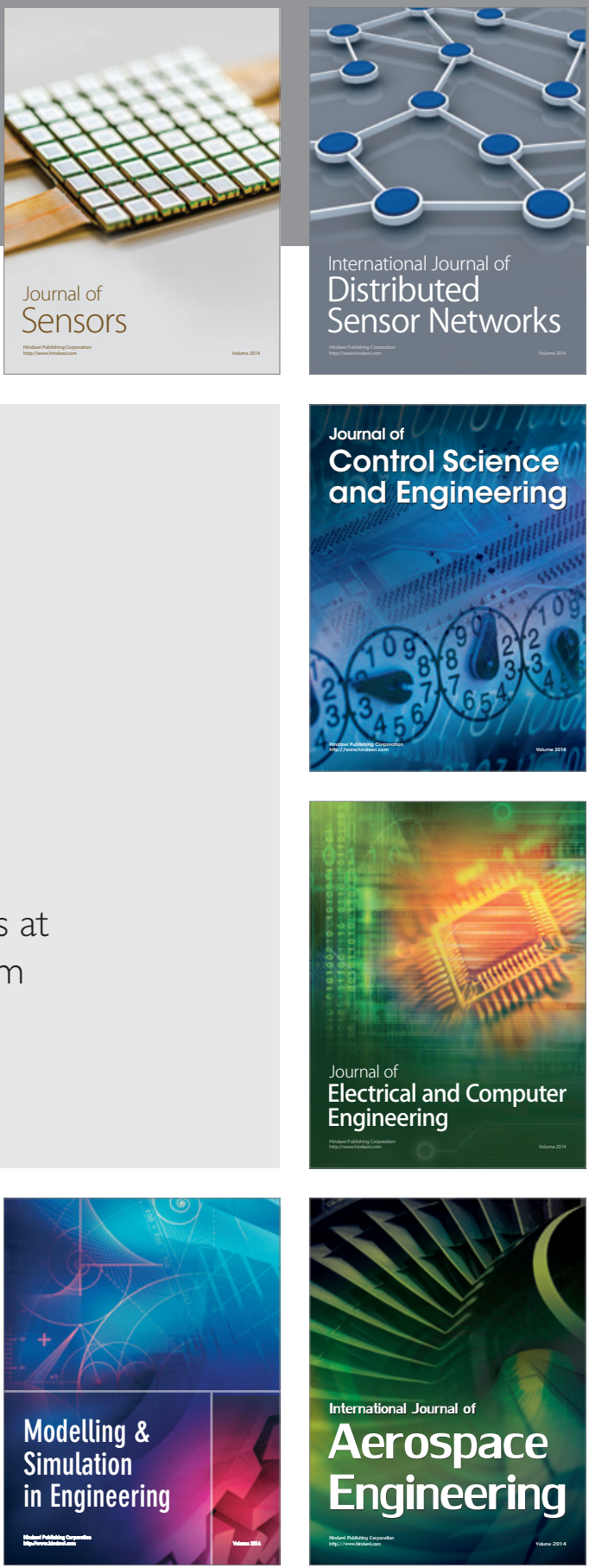

Journal of

Control Science

and Engineering
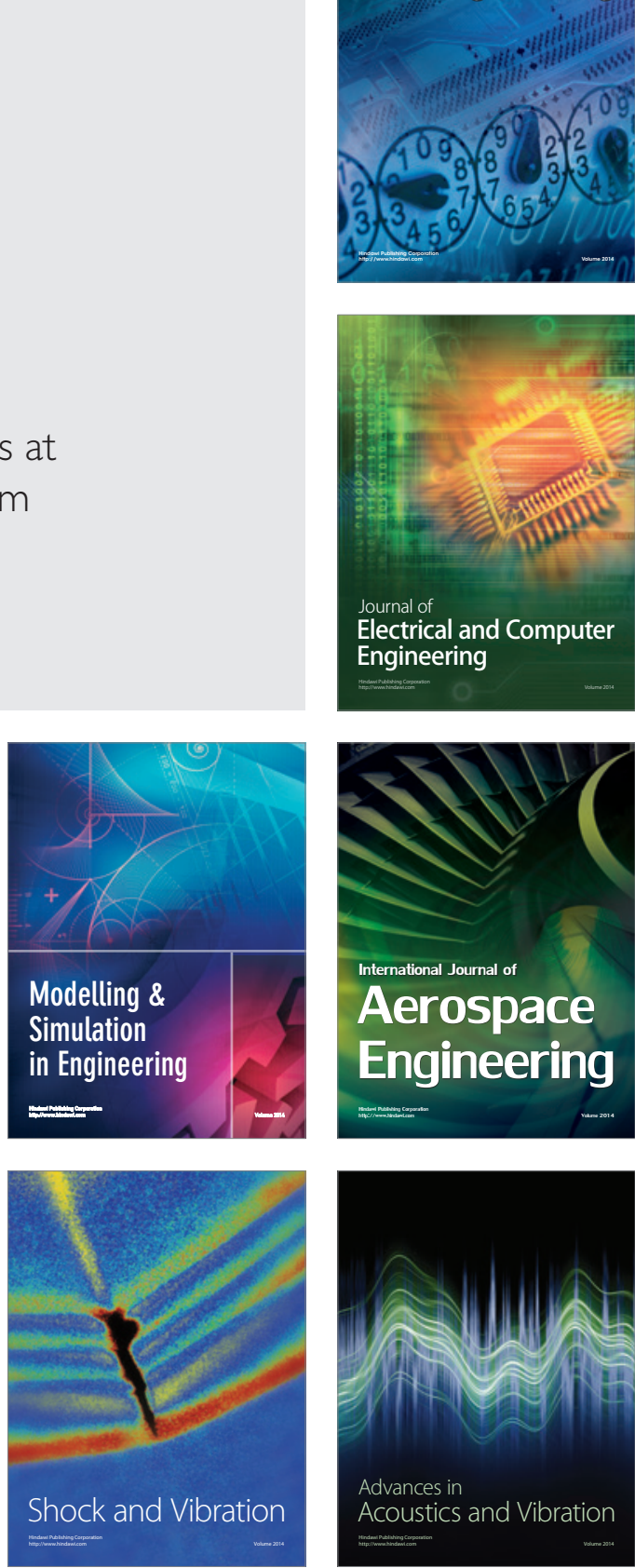